
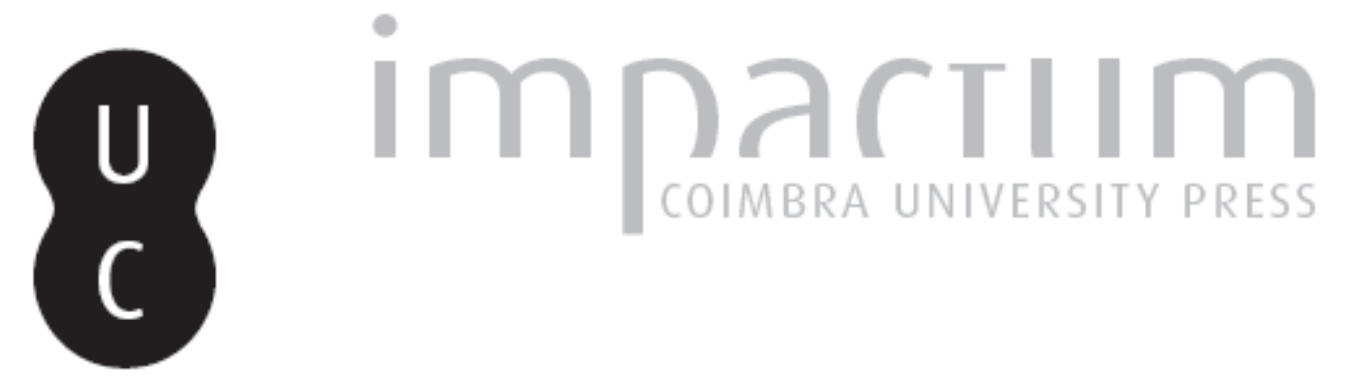

\title{
Revueltas y revoluciones en España: (1766-1874)
}

Autor(es): $\quad$ Gil Novales, Alberto

Publicado por: Imprensa da Universidade de Coimbra

URL persistente:

URI:http://hdl.handle.net/10316.2/45082

DOI:

DOI:https://doi.org/10.14195/2183-8925_7-2_13

Accessed : $\quad$ 26-Apr-2023 11:06:39

A navegação consulta e descarregamento dos títulos inseridos nas Bibliotecas Digitais UC Digitalis, UC Pombalina e UC Impactum, pressupõem a aceitação plena e sem reservas dos Termos e Condições de Uso destas Bibliotecas Digitais, disponíveis em https://digitalis.uc.pt/pt-pt/termos.

Conforme exposto nos referidos Termos e Condições de Uso, o descarregamento de títulos de acesso restrito requer uma licença válida de autorização devendo o utilizador aceder ao(s) documento(s) a partir de um endereço de IP da instituição detentora da supramencionada licença.

Ao utilizador é apenas permitido o descarregamento para uso pessoal, pelo que o emprego do(s) título(s) descarregado(s) para outro fim, designadamente comercial, carece de autorização do respetivo autor ou editor da obra.

Na medida em que todas as obras da UC Digitalis se encontram protegidas pelo Código do Direito de Autor e Direitos Conexos e demais legislação aplicável, toda a cópia, parcial ou total, deste documento, nos casos em que é legalmente admitida, deverá conter ou fazer-se acompanhar por este aviso.

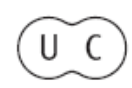




\section{REVISTA DE HISTORIA DAS IDEIAS 7}

\section{REVOLTAS E REVOLUCOẼS}

\section{**}

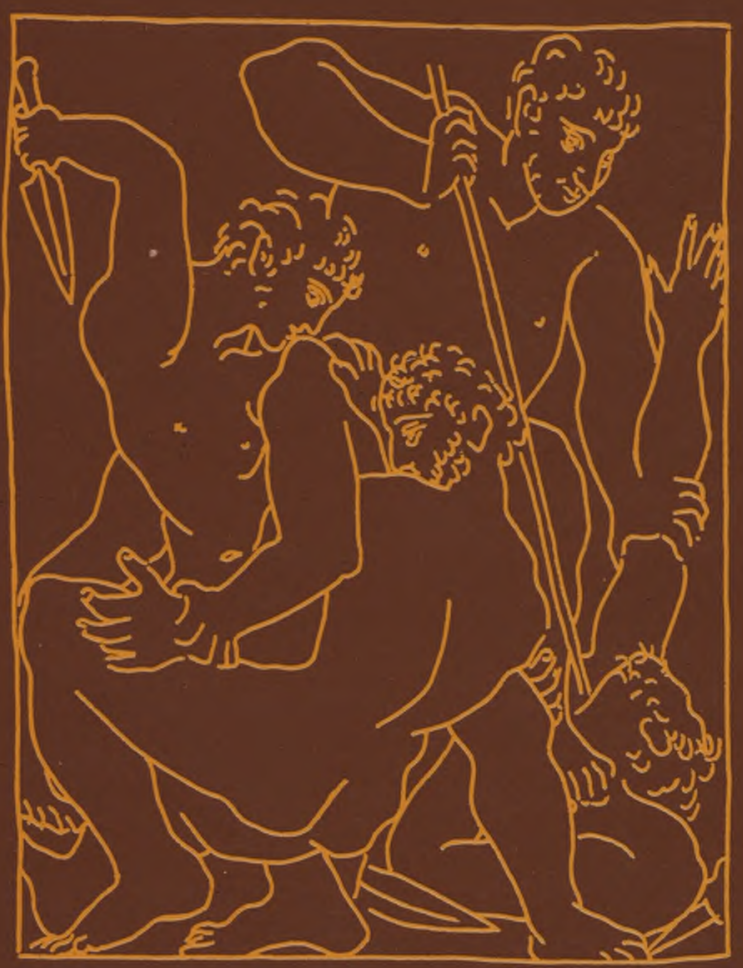

INSTITUTO DE HISTÓRIA E TEORIA DAS IDEIAS FACULDADE DE LETRAS 


\section{REVUELTAS Y REVOLUCIONES EN ESPAÑA (1766-1874)}

El título de este trabajo podría ser también: Revueltas y revoluciones en la formación de la España actual. Ciertamente que todo el pasado de un país contribuye a formar su estado presente, $\mathrm{y}$ en este sentido incluso las investigaciones arqueológicas lo cobran para entender determinados rasgos, persistentes o no, en nuestra historia. Y por supuesto que revueltas y revoluciones, alteraciones como se decía con palabra clásica, tuvieron lugar en el solar de Hispania a todo lo largo de la existencia de sus pueblos. En la España moderna, ¿cómo no mencionar a los comuneros de Castilla, los agermanados de Valencia y Mallorca, las alteraciones de Aragón con motivo de la huida de Antonio Pérez, etc?, movimientos que serán ampliamente recordados en el siglo XIX. ¿Cómo no recordar la crisis del siglo XVII, con las sublevaciones de Cataluña, Portugal y Nápoles? - la famosa crisis de la Monarquía Hispánica de los Felipes, en la que tanto insisten los historiadores de hoy. ¿Cómo no hablar del carácter popular y multitudinario que tomó entre nosotros la Guerra de Sucesión?

Razones no faltan para recoger todos estos movimientos, y aun los medievales e incluso de la Antigüedad, a la hora de trazar la historia revolucionaria o tumultuaria de la España actual. No obstante, y sin perjuicio de hacer quizá alusiones rápidas a ese pasado, creo que no debemos perdernos en él, sino que por el contrario debemos tomar como punto de partida el que marca el comienzo del fin del Antiguo Régimen, es decir 1766. Las Comunidades de Castilla han sido definidas (*)

(*) Facultad de Ciencias de la Información de la Universidad Complutense de Madrid. 


\section{Revoltas e Revoluções}

como una revolución burguesa temprana $i^{1}$ ) - ya ello deben su rabiosa actualidad en el siglo XIX. Pero en ningún momento ese movimiento puso en peligro la existencia misma del Antiguo Régimen - como no sea que lo interpretemos como un aviso a tres siglos vista.

Decididamente mejor es partir de los llamados Motines de Esquiladle (es decir, contra Esquiladle) en 1766, porque aunque tampoco con ellos desaparece el Antiguo Régimen, sin embargo su naturaleza a la vez arcaica y modernísima, su incidencia geográfica, su dimensión - las más grandes alteraciones sociales de Europa hasta la Francia de 1789, al decir de Pierre Vilar (2) - confiere a estos motines el significado inequívoco de que con ellos empieza a cuartearse la fábrica de nuestro Antiguo Régimen. Pierre Vilar y Gonzalo Anes ( $\left.{ }^{3}\right)$ han insistido en que el Motín madrileño contra Esquilache es un motín de subsistencias, originado en la ordenanza de libre circulación de los granos, es decir, algo muy semejante a la guerre des farines francesa. Otros han visto sobre todo el aspecto político, de conjura aristocrática y antiilustrada $\left({ }^{4}\right)$. La interpretación tradicional, presente ya al día siguiente de los acontecimientos y en toda la tradición liberal, echó la culpa a los jesuitas; y de aquí la expulsión de éstos en 1767. Recientemente Giovanni Stiffoni, al utilizar una fuente hasta ahora no empleada a este respecto, las relaciones de los embajadores vénetos, ha venido a confirmar documentalmente la tesis de Pierre Vilar $\left(^{5}\right)$.

Observemos que los motines de 1766 se extendieron no solamente a Madrid, sino a Aragón, Castilla, Guipúzcoa - las machinadas vascas - Valencia y Murcia, llegando incluso a Andalucía, en donde asistimos al insólito espectáculo de la insubordinación de todo un regimiento en Sevilla; lo cual tiene,

O Cf. Manfred Kossok, "Comuneros und Gemianías. Spanien an der Schwelle der frühbürgerlichen Révolution», Zeitschrift fur Geschichte, Heft 1, 1979, pp. 46-65.

O Cf. Pierre Vilar, «El 'motín de Esquiladle' y las crisis del Antiguo Régimen", Revista de Occidente, 107, Febrero de 1972.

(3) Vilar, ob. cit., y Gonzalo Anes, «Antecedentes próximos del motín contra Esquilache», Moneda y Crédito, 128, Marzo de 1974, pp. 219-224.

$\left({ }^{4}\right)$ Cf. Vicente Rodríguez Casado, «La 'revolución burguesa' del XVIII español», Arbor 61, Enero de 1951; y Laura Rodríguez Díaz, «The Spanish Riots of 1766», Past and Present 59, mayo 1973, pp. 117-146.

(5) Cf. Giovanni Stiffoni, «Diplomazia ed 'opinione pubblica' veneziane di fronte ad una crisi deH'assolutismo riformatore: le rivolte di Madrid e provincie del 1766", Nuova Rivista Storica, V-VI, 1982, pp. 511-546. 


\section{Revueltas y Revoluciones en España}

por lo menos, carácter premonitorio del futuro papel del Ejército en España ( $\left.{ }^{6}\right)$.

Después de la gran prueba que el año 1766 había planteado a la Monarquía, pareció entrar ésta en un período de normalidad, con las grandes reformas ilustradas de Carlos III y su continuación bajo Carlos IV. La resistencia a las reformas, que de tan aguda manera conmocionará a la España del siglo XIX, no da lugar en esta época a graves alteraciones del orden, aunque los intereses amenazados no dejan de hacer sentir su presencia, presagiando acaso el futuro. El año 1776 tiene lugar la fulminante destitución de Olavide, con el proceso inquisitorial consiguiente $-\mathrm{y}$ naturalmente todo el equipo gobernante era objeto de vigilancia, y aun quizá de algo más grave: de momento, contenido $\left({ }^{7}\right)$.

De manera que la Ilustración encontraba su correctivo en la Inquisición, y aunque la caída de Olavide no significó el abandono total de la política ilustrada $\left({ }^{8}\right)$, sin embargo indicaba bastante bien la función que en la sociedad española empezaba a jugar la Iglesia. Actitud ya manifiesta en la dramática representación del Obispo de Cuenca, D. Isidro de Carvajal y Lancaster, también de 1766, en la que el piadoso Prelado se quejaba de «la persecución de la Iglesia, saqueada en sus bienes, ultrajada en sus Ministros, y atropellada en su inmunidad», a la que contestó el gobierno con un Memorial-ajustado $\left({ }^{9}\right)$.

Esto pareció de momento disensiones originadas en el celo por el bien de la Patria, y ciertamente el reinado de Carlos III no presentó ninguna nueva revolución o contrarrevolución (en España; sí en América). Al año de su muerte, 1788, estallaba la

(6) Remito a Alberto Gil Novales, Política y Sociedad, en Manuel Tuñón de Lara (dir.), Historia de España VII, Centralismo, Ilustración y agonía del Antiguo Régimen (1715-1833), Barcelona, Labor, 1980, 221-227. (en adelante Centralismo).

( ${ }^{7}$ Cf. Marcelin Défourneaux, Pablo de olavide ou VAfrancesado, Paris, PUF, 1959; y del mismo: «Régalisme et Inquisiton: une campagne contre Campomanes», Mélanges à la mémoire de Jean Sarrailh, Paris, Institut d'Etudes Hispaniques, 1966, I, pp. 299-310.

(8) Cf. Franco Venturi, Settecento riformatore. IV. La caduta delVAntico Regime (1776-1789), Tomo I, I grandi stati delvoccidente, Turin, Einaudi, 1984, p. 243 y ss.

C) Cf. Memorial-ajustado hecho de orden del Consejo-Pleno, a instancia de los Señores Fiscales, del expediente consultivo visto por remisión de Su Mag. a él. sobre el contenido, y expresiones de diferentes Cartas del Rev. Obispo de Cuenca D. Isidro de Carbajal y Lancaster. Con licencia. Barcelona, Thomas Pif errer, 1768. El ejemplar de mi propriedad lleva al final una nota ms., en la que se da cuenta de la muerte del obispo en 1771 , y se ponderan sus virtudes ejemplares, modelo para prelados y sacerdotes. 
revolución francesa, que por miedo y rabia va a lanzar a la más extrema reacción a algunos de los ilustrados de mayor nombradla, a comenzar por Floridablanca $\left({ }^{10}\right)$. La guerra contra la República francesa en 1793, con su emoción patriótica, fue aprovechada también por las fuerzas reaccionarias para movilizar al pueblo, no sólo contra la Francia regicida, sino contra las mismas ideas de la Ilustración monárquica española $\mathrm{O}^{1}$ ). Un título del famoso Fray Diego José de Cádiz indica muy bien el espíritu con el que la Iglesia, o un sector de ella — porque convendrá matizar — se dispone a encarar la llegada del mundo contemporáneo: El soldado católico en guerra de religión, $1794\left({ }^{12}\right)$.

Sin embargo una clase muy diferente de alteraciones tenía lugar en España, las derivadas de la escasez de primeras materias, típicas de toda economía de Antiguo Régimen; como los célebres motines de Barcelona del año, precisamente, 1789 (13). Carentes de finalidad social o política a largo plazo, no dejaron sin embargo estos motines de preocupar a las autoridades. Sintomático parece el caso de los «alborotadores de la Ulloa», protesta antifiscal manipulada o aprovechada por la Iglesia: al grito de Viva el Rey: viva la Ulloa: muera la Unica (contribución) estos gallegos de la provincia de Lugo llegaron a caer clamorosamente sobre Orense el 22 y 23 de Noviembre de 1790, siendo apaciguados por la mediación eclesiástica (13a). Mayor dimensión tuvieron los motines valencianos, de 1793-1794 y 1800-1801. El primer motín, el de 1793, «año de precios altos», fue una conmoción contra los sacerdotes franceses - España había entrado en guerra con la República - en la que parece adivinarse una intriga del Capitán General, Duque de la Roca, contra el Arzobispo. Al año siguiente, 1794, la orden de formación de un cuerpo de Milicias, llamado de Voluntarios Honrados, confiado por el Capitán General a tres magistrados de la Audiencia, entre ellos el fiscal Don Juan Romero Alpuente, dio lugar a la protesta de éstos, ya que el reclutamiento se hacía a expensas de los reclutados, gente humilde que no podían pagar elevadas cantidades. El Duque de la Roca metió en la cárcel a los magistrados, y de aquí se derivó un motín contra el Capitán Ge-

(10) Cf. Alberto Gil Novales, ob. cit., pp. 251-252.

(u) Cf. ob. cit. en n. ant., pp. 254-256.

(12) Ecija, Imp. de D. Benito Daza, 1794. Palau registra otras eds. de 1794, 1795, 1813, 1814, 1815, 1840 y 1895.

(13) Cf. Irene Castells, «Els rebomboris del pa de 1789 à Barcelona», Recerques I, 1970, pp. 51-82.

(13a) Cf. Juan Manuel Bedoya: Retrato histórico del Emmo. Excmo. e limo. Señor Don Pedro de Quevedo y Quintano, Madrid, Imp. que fue de Fuentenebro, 1835. 


\section{Revueltas y Revoluciones en España}

neral y a favor de los magistrados, al que se sumó la nobleza valenciana, lo que obligó a Godoy en 1795 a ordenar la liberación de los tres magistrados, y en definitiva a dar marcha atrás $\left({ }^{14}\right)$.

El miedo a la Revolución francesa, unido a las dificultades económicas de buena parte de la población, explican estos desórdenes. Carácter diferente tiene la conspiración de Juan Picornell, amada del «Cerrillo de San Blas», que buscaba proclamar la República, según la interpretación tradicional, o por lo menos una Monarquía Constitucional. Aunque la conspiración lleve una fecha concreta, Febrero de 1795, venía incubándose de tiempo atrás: así lo demuestra el Catecismo político, de 1787, que descubrió Iris M. Zavala. Pero la amplia represión provocada por esta intentona se relaciona naturalmente con el miedo a la Revolución francesa (14a).

La aparición en Galicia de una burguesía que plenamente podemos llamar feudal, por usar con los campesinos de los peores métodos del antiguo orden, explica que en esa región se den motines populares antiburgueses, como los que en 1797 y 1798 atacaron la empresa de Sargadelos, del famoso Don Antonio Raimundo Ibáñez. La intervención de los notables de la comarca en el motín, entre ellos muchos eclesiásticos, confiere a estos sucesos el aspecto de «ensayo general de la guerra civil que apenas treinta años más tarde había de desgarrar el país», según ha puesto luminosamente de relieve María Rosa Saurín de la Iglesia. Ibáñez no llegó hasta la guerra civil: fue asesinado por sus vasallos en 1809 (14b).

Por un problema semejante, pero con otro planteamiento inicial, en Diciembre de 1800 estalló en Valencia un motín contra el intendente, el cual tuvo que escapar disfrazado; motín que se reprodujo, y se comunicó a otros puntos además de la capital, con motivo de la recluta de las llamadas Milicias Provinciales, que violaba un supuesto privilegio foral, pero que al ${ }^{*} 1$

Cf. Manuel Ardit Lucas, Revolución liberal y revuelta campesina, Barcelona, Ariel, 1977, pp. 96-98; y mi Introdución a Juan Romero Alpuente, Historia de la revolución española (en prensa).

(14a) Cf. Iris M. Zavala: «Picornell y la revolución de San Blas: 1795», Historia Ibérica, I, 1973, 35-58; la misma: «Cabarrús y Picornell: un documento desconocido", Cuadernos hispanoamericanos, Junio 1969, 774-782; M.a Jesús Aguirrezábal y José Luis Cornelias: «La Conspiración de Picornell», Revista de Historia Contemporánea, Sevilha,

1, Die. 1982. 7-39; Giovanni Stiffoni: «Dal 'Motín' contro Esquiladle al 'Motín' di Aran juez: la transí ormazione di un mod ello nella crisi déll'Antico Regime in Spagna", Annali di $\mathrm{Ca}^{\prime}$ F ose ari, XXI, 1-2, 1982, 200-204.

(«b) cf. María Rosa Saurín de la Iglesia: Reforma y reacción en la Galicia del siglo XVIII (1764-1798), La Coruña, «La Voz de Galicia», 1983, pp. 135-165. 


\section{Revoltas e Revoluções}

mismo tiempo atentaba contra el carácter aristocrático del mando. En Agosto y Septiembre de 1801 este motín se transformó en una jacquerie campesina, que anuncia ya los intensos movimientos de 1808 , en la que apareció un cabecilla, persona real, pero rápidamente mitificado bajo el apelativo de Pep de VHorta. En nombre del Rey y a las órdenes de Pep de VHorta, la revuelta adquirió clara connotación antifeudal $\left({ }^{15}\right)$.

La prepotencia de Godoy y la presión francesa iban muy pronto a conducir a estallidos revolucionarios. En Octubre de 1807 la famosa Causa del Escorial - conspiración de Fernando contra su padre Carlos IV — indicaba que incluso en la cúspide monárquica del país la situación se iba deteriorando. Unos meses después, ya con media España ocupada por las tropas de Napoleón, se produjo el motín de Aranjuez - 17-19 Marzo 1808 contra Godoy, que obligó a Carlos IV a abdicar. Se trató de un motín popular, por el odio al valido todopoderoso, pero instigado por cierto sector aristocrático, que políticamente tomaba la forma del partido fernandino. El nombre del Tío Pedro - Conde del Montijo - simboliza bastante bien la conjura para convertir España en dominación directa de la aristocracia, que estará presente en sus actuaciones durante la Guerra de la Independencia (ie).

La cual, desde el punto de vista que aquí nos interesa, es una extraordinaria concatenación de motines y revueltas. La artera ocupación del país por los franceses produce creciente descontento, que sabrán aprovechar para sus fines las fuerzas reaccionarias, que explotarán para ello la fibra de lo patriótico. Pero la Guerra de la Independencia no se reduce a este aspecto, sino que es también una formidable movilización popular, aparte de representar, por la presencia de tres ejércitos en nuestro suelo, una gran destrucción de la riqueza material de España, factor que va a retrasar durante largos años el progreso nacional

La insurrección madrileña del Dos de Mayo de 1808 no es meramente una conmoción popular contra el invasor, motivada por la salida de los últimos miembros de la familia real camino de Francia, sino que es, como justamente se ha dicho muchas veces, un símbolo de toda la contienda. Madrid empieza así a mostrar revolucionariamente rango de capital de España, que

(15) Cf. Ardit Lucas, ob. cit., pp. 98-119.

(1\#) Cf. A. Gil Novales, Centralismo, pp. 262-263, y Claude Morange: «EI Conde del Montijo durante la Guerra de la Independencia. Apuntes para su biografia», Trienio 2, Nov. 1983, pp. 3-40; del mismo, «El Conde del Montijo. Reflexiones en torno al «partido» aristocrático de 1794 a 1814», Trienio, n. ${ }^{\circ} 4$, Nov. de 1984, pp. 13-67. 
sabrá refrendar a lo largo de todo el siglo XIX, hasta 1936. Insurrección seguida de represión - los fusilamientos del 3 de Mayo, inmortalizados por Goya - que no hace más que sembrar más indignación, y como retruque, más coraje nacional. El pueblo, víctima pero protagonista, ha hecho su aparición en la escena histórica.

De repente, todo se precipita en España. Movimientos, motines y proclamaciones de Gijón y Oviedo - 5 y 9 de Mayo con evidente emoción antifrancesa, y la aparición de una Junta, que envía delegados a Inglaterra a negociar la inversión de las alianzas. La Coruña - 29-30 de Mayo - con formación de Junta, origen de la Suprema de Galicia. Santiago de Compostela, con movimiento de origen popular, pero que termina típicamente con su Junta presidida por el Arzobispo. Santander - 27 de Mayo - idéntico caso. Badajoz - 30 de Mayo - asesinato del Capitán General Conde del Fresno. Sevilla - 27 de Mayo - con proclamación de la titulada Junta Suprema de Gobierno de España e Indias, con influjo inmediato sobre Córdoba, Jaén y Granada, y con envío también de representantes a Inglaterra. Cádiz - 29 de Mayo - asesinato del Capitán General Marqués del Socorro, y formación de Junta. Cartagena, lo mismo (el asesinado se llamaba Don Francisco de Borja). En Murcia preside el viejo Conde de Floridablanca. La violencia se ceba en Valencia, con la acción del canónigo Baltasar Calvo - asesinato del barón de Albalat y de 300 franceses. Junta en Palma de Mallorca - 30 de Mayo - presidida típicamente por el Capitán General. En Lérida - finales de Junio - se forma la Junta General del Principado de Cataluña, ya que Barcelona se halla ocupada por los franceses. Juntas en Aragón, con la de Zaragoza el 26 de Mayo. Destitución del Capitán General en Canarias, y formación de Junta presidida por el nuevo Capitán General.

Sobre el fenómeno que las Juntas representan en el orden militar y político, ya muy estudiado $\left({ }^{17}\right)$ - aunque nos falten datos de análisis concreto $\left({ }^{18}\right)$ - sólo insistiré en el hecho de que en todas ellas el movimiento popular aparece controlado

(1T) Cf. Jean-René Aymes, La Guerre d'indépendance Espagnole, Paris, Bordas, 1973, pp. 72-74; Alberto Gil Novales, «El problema de la revolución en el liberalismo español (1808-1868)», Estudios de Historia social, 22-23, Julio Dic. 1982, pp. 12 y ss; del mismo Centralismo, 270.

$\left({ }^{18}\right)$

Cf. Antonio Moliner Prada, Estructura, funcionamiento y terminología de las Juntas supremas provinciales en la guerra contra Napoleón. Los casos de Mallorca, Cataluña, Asturias y León, tesis doctoral inédita leída en la Universidad Autónoma de Barcelona en 1981. 


\title{
Revoltas e Revoluções
}

por las clases superiores, y que el recurso a formar Juntas, típico de todo el siglo XIX, pasará del elemento feudal a la burguesía, y servirá para burlar al pueblo protagonista los efectos buscados con su acción.

Pero de momento las Juntas son un poderoso elemento de encauzamiento y movilización controlada del pueblo, y de soberanía desparramada por todo el país. Las necesidades de la guerra, y la conciencia de unidad nacional que se había ido forjando en la centuria anterior, lleva a estas Juntas a crear la Central - 25 de Septiembre de 1808. Esta medida determinó nada menos que la aparición del golpismo militar, que trataba de impedirla, cuando el Capitán General de Castilla y León, Gregorio de la Cuesta, manda detener por subversivos a los delegados de León en la Central. Mejor que ningún comentario, bastará reproducir un párrafo de la carta que el también general Castaños le escribe a Cuesta para hacerle desistir de su acción:

\begin{abstract}
«....si los generales, a quienes está confiada la fuerza militar para derrotar a nuestros enemigos, se han de hacer independientes $y$ aun superiores a la autoridad civil, procediendo por sí mismos contra las personas en quienes reside, no se diga ya que los objetos para que se arman los pueblos y se crean los ejércitos son la defensa de Fernando VII, la independencia y libertad de España, ni la conservación de las leyes; sino que se trata de establecer una anarquía militar, que después de derramar torrentes de sangre, nos ha de hacer caer en las manos de nuestros enemigos, y nos ha de precipitar en el despotismo y la esclavitud.» $\left({ }^{19}\right)$.
\end{abstract}

Palabras que el tiempo se encargó de hacer proféticas.

No podemos seguir aquí todos los avatares de la Guerra de la Independencia, con la acción de las guerrillas y la reunión de las Cortes de Cádiz, pero naturalmente habremos de tenerlas presentes para entender los acontecimentos posteriores. Las Cortes de Cádiz habían tratado de convertir España en una monarquía constitucional. Quedaba la incógnita de cuál sería la actitud de Fernando VII, a su vuelta de Valencey, en 1814. La Constitución tenía muchos enemigos, que deseaban volver sin más al Antiguo Régimen. Y así el 17 de Abril de 1814 el Capitán General Francisco Javier Elío, en Valencia, se pronunció en

(19) Cf. Impugnación que hacen los individuos que compusieron la Suprema Junta Central al Manifiesto del Capitán General Don Gregorio de la Cuesta, Cádiz, Imp. del Estado-Mayor-General, 1812, p. 6 de los Documentos puestos a modo de Apéndice. La carta de Castaños está fechada en Madrid a 18 de Septiembre de 1808. 


\section{Revueltas y Revoluciones en España}

favor del absolutismo, lo cual, unido al Manifiesto de los Persas - 69 diputados de las Cortes ordinarias que invitaban al Rey a lo mismo - permitió a Fernando dar el célebre Decreto del 4 de Mayo por el que se abolía la Constitución, mientras otro de la misma fecha suprimía la libertad de expresión. El golpe de Estado del Rey fue protegido por las tropas de Samuel Whittingham, general británico al servicio de España.

La pérdida de la libertad fue fácil. Recobrarla no lo será tanto. Aparte las tropas de Elío y del inglés, el resto de los militares habían estado pasivos, disponiéndose sólo a obedecer lo que resultase. Los años siguientes cambiarían en gran manera esta actitud. Parece ser que contra el cumplimiento del Decreto se suscitó un motín en el Barrio de Santa María de Cádiz para forzar a la resistencia al gobernador militar de la plaza. La cosa no pasó de intentona, y su principal autor tuvo que refugiarse en Gibraltar $\left({ }^{20}\right)$.

Inmediatamente comenzaron las conspiraciones. La primera fue la de Francisco Espoz y Mina, antiguo guerrillero, que se alzó en Puente la Reina el 25 de Septiembre de 1814, pero fracasó ante Pamplona y tuvo que refugiarse en Francia. El carácter de Mina antes de esta fecha — se sabe que había ordenado el fusilamiento del libro de la Constitución — y en su actuación posterior, arrojan muchas dudas sobre la naturaleza de esta acción. Que Espoz y Mina no era un liberal convencido, su vida lo demostró; pero en 1814, si quería tener éxito, su actuación sólo podía ser liberal. El marquesito Juan Díaz Porlier logró fugarse del Castillo de San Antón, en donde estaba preso por liberal, y al frente de la guarnición de la Coruña proclamó la Constitución el 19 de Septiembre de 1815. Sólo en El Ferrol encontró eco, y en consecuencia, derrotado y juzgado, fue ajusticiado a los pocos días. En Febrero de 1816 se descubrió la conspiración llamada del triángulo, cuyo agente principal era Vicente Ramón Richart, y cuyo propósito se dice que era matar al rey. Aparte su índole triangular, poco sabemos de esta conspiración y de sus pretendidas conexiones en las altas esferas, a pesar de haber sido publicada y analizada su causa dos veces (21).

(20) Cf. Alberto Gil Novales, Las Sociedades patrióticas, Madrid, Tecnos, 1975, p. 803 (entrada Diego Correa, quien habría sido el dirigente del motín). En adelante, Soc. Patr.

(n) Cf. «Causa contra D. Vicente Ramón Richart, D. Baltasar Gutiérrez, D. Ramón Calatrava, D. Juan Antonio Yandiola, D. Simón la Plaza y otros, formada en 1816 sobre conspiración contra la persona del Rey», en Colección de las causas más célebres e interesantes de los mejores modelos de alegatos, actuaciones fiscales, interrogatorios y las más elocuentes defensas en lo civil y criminal del foro español, 
Mayor resonanda alcanzó la conspiración tramada por los generales Don Luis Lacy y Don Francisco Milans del Bosch, quienes en Abril de 1817 trataron en Barcelona y Gerona de restablecer la Constitución. En este movimiento encontramos ya una importante participación burguesa. Habiendo fracasado Milans pudo escapar, mientras Lacy era hecho prisionero. Una segunda conspiración, destinada a darle libertad, fracasó también, y Lacy fue ajusticiado en el castillo de Bellver, en Mallorca, por orden de Castaños cuando todo el mundo esperaba el perdón. Castaños ganó así ante sus coetáneos fama de general absolutista amigo de derramar la sangre de sus compañeros de armas. En pocos años, el vencedor de Bailén, el increpante de Cuesta, se había transformado en un servil de nota. En estos años difíciles, los acontecimientos parecían no tolerar medias tintas.

Nueva conjuración, la del coronel Vidal en Valencia a comienzos de 1819. El proprio capitán general Elío apuñaló a Vidal, que murió a consecuencia de las heridas; sus compañeros fueron ejecutados. Todas estas conjuraciones fueron seguidas de represión, con detenciones en cadena; y sin embargo, como hemos visto, hubo casi una conjuración cada año, mientras la Inquisición, los escándalos gubernativos y la falta de horizontes políticos desprestigiaban al régimen. Éste llegó a preocuparse por su propria imagen en Europa, y acaso a esto se debió que cuando se descubre la siguiente conspiración, la llamada del Palmar, 7 Julio de 1819, aunque hubo detenciones, no hubo muertes, y el gobierno mostró una extraña parsimonia.

Protagonista de la conjuración del Palmar había sido el cuerpo expedicionario reunido en torno a Cádiz, para reconquistar Buenos Aires, llave de la América del Sur. Los mismos elementos van a ser los autores de la Revolución de 1820, hasta el punto de que podemos considerar como uno solo a los dos movimientos. Entre las tropas destinadas a Ultramar habían cundido las ideas liberales, en parte como consecuencia de la democratización del ejército operada durante la Guerra de la Independencia: al querer volver el absolutismo al ejército aristocrático de Antiguo Régimen, paralizando la promoción de los oficiales de otra extracción, era lógico que éstos se sintiesen dispuestos a la acción. Además hasta estas tropas llegan las noticias sobre las terribles condiciones de la guerra colonial, y también la propaganda, y a veces el dinero de los gobiernos

francés e inglés por una Sociedad de Jurisconsultos. Parte española. Madrid, Libr. de D. Leocadio López, 1863, VIII, pp. 77-291; y M. Pilar Ramos Rodríguez, La conspiración del triángulo, Univ. de Sevilla, 1970 . 


\section{Revueltas y Revoluciones en España}

insurrectos, y en consecuencia surge un sentimiento de solidaridad entre los combatientes por la Libertad a ambas orillas del Atlántico: para Riego y los suyos, la vuelta a la Constitución resolverá los problemas tanto de América como de España.

De este modo con el pronunciamiento de Riego el 1 dé Enero de 1820 en Cabezas de San Juan (Sevilla) empieza el llamado Trienio liberal, y podemos hablar por primera vez acaso de revolución. Pero conviene ver en síntesis el desarrollo de los acontecimientos. El pronunciamiento de Riego, seguido por su famosa marcha por Andalucía, aunque en sí mismo nó logró el triunfo, sirvió para que el movimiento repercutiese en otras partes de España: La Coruña, 21 de Febrero; Zaragoza, 5 de Marzo; Barcelona, 13 de Marzo; Pamplona, 11 de Marzo; Cartagena y Murcia, Sevilla, Granada, Valladolid y Madrid. En todas estas ciudades actuó el ejército en sentido liberal, o acaso mejor sectores del mismo; hubo también alguna colaboración civil, en ocasiones muy intensa, y en Barcelona se señala la presencia de los gremios. Después de cada pronunciamiento generalmente se forma una Junta. Fernando VII se decidió a aceptar la Constitución de Cádiz el 7 de Marzo de 1820, pero un motín del día 9 entregó el poder a una Junta Provisional, presidida por el Arzobispo de Toledo, que inmediatamente reclamó para sí la soberanía sobre toda España.

Este resultado, triunfo de la Constitución pero con el poder escamoteado a los revolucionarios, se había dado ya en algunas actuaciones locales, Zaragoza, Barcelona, Pamplona, etc., y llega a su madurez el 9 de Marzo con la Junta provisional. ¿Revolución? Sí, en lo formal, porque vuelve a régir la Constitución gaditana, habrá elecciones y Cortes y vida política y esperanza de libertad. Por primera vez el pueblo, todas las clases sociales, empieza a vivir una vida política abierta, y hay lógicos enfrentamientos de intereses contrapuestos, y apasionamiento, escrito y oratorio, por manifestar las opiniones. La Revolución amenaza con extenderse al pueblo, y yo creo que esta amenaza es decisiva porque muchos interpretarán los sucesos nacionales, miméticamente, a la luz de lo sucedido en Francia en su gran revolución. La burguesía nacional, débil y mal cohesionada, puede hacer avanzar en las Cortes su propio programa, dando origen a una legislación que será fundamental para todo el siglo XIX; pero vivirá entre dos temores, el del pueblo y el de la contrarrevolución realista. Desde el punto de vista revolucionario - empleemos ya la expresión: de revolución burguesa - los gobiernos liberales dejan insatisfechos a sus propios seguidores, actúan con recelo y con frecuencia contra el pueblo - el cual está lejos de ser un pueblo unívoco, pues aparte la separación geográfica — tradiciones, cultura - entre 
unas regiones y otras, hay una separación fundamental, difícilmente salvable, entre pueblo urbano y campesinado.

Todo esto explica la difícil vida política del Trienio liberal, la serie de intentos contrarrevolucionarios y de otro cariz, que aparecen ya en 1820, pero se generalizan en 1821. En 1820 y 1821 aparecen las partidas absolutistas, avanzadilla del carlismo - incluso el nombre de Don Carlos como rey de España se propone por primera vez en 1821 - expresión de la crisis campesina, que la política liberal no sabrá remediar. Al no atreverse la burguesía a acaudillar decididamente al campesinado en la lucha contra el orden feudal, y contentarse de momento con soluciones intermedias, sobre el campesino cae lo peor de los dos sistemas; que la timidez y falta de horizontes en ia solución de los problemas de la Hacienda, no hará más que agravar. La Iglesia reaccionaria sabrá aprovecharse de la coyuntura, convirtiendo a los campesinos en $f$ cotas, o defensores de la fe.

El pueblo urbano, sobre todo, sinceramente liberal, atemorizado con la posibilidad de la recaída en una situación semejante a la de 1814, reacciona contra las claudicaciones de los gobiernos, sobre todo el de 1821, promoviendo unos vastos movimientos de desobediencia cívica, con centro en Cádiz y Sevilla, que afectó junto a estas ciudades a Córdoba, Cuenca, La Coruña, Zaragoza, Barcelona, Valencia, Cartagena, Murcia, Granada y Badajoz, movimientos populares urbanos, sobre los cuales ya Marx llamó la atención (22).

Cuando el movimiento popular decae, a comienzos de 1822, tiene lugar la represión oficialmente orquestada contra los patriotas, preparación a su vez de la gran contrarrevolución de 30 Junio - 7 Julio de 1822; adelantada en algunos puntos, como Valencia, por impaciencia a Mayo del mismo año. Este desequilibrio temporal y la ausencia de identidad de miras entre los contrarrevolucionarios, ya que unos querían volver lisa y llanamente al Antiguo Régimen, y otros se contentaban con implantar un régimen de cámaras, explica la derrota de la contrarrevolución, en Madrid, el 7 de Julio de 1822. Pero se hace necesario hablar también para entenderla de la movilización liberal de los barrios de la capital, la aparición de las guerrillas urbanas, el No pasarán y el heroísmo innominado - todo tan moderno - de las clases bajas, sin más organización que la Milicia Nacional y el Ayuntamiento - frente al Rey y la fami-

(") Cf. Karl Marx, «La inter venció à Espanya», presentado por Jaume Torras, Recerques, 6, Barcelona, 1976, pp. 7-11 (fragmento de un texto de 1864, incorporado en alemán a las Marx Engels Werke, Berlín, 1970. 


\section{Revueltas y Revoluciones en España}

lia real, los palaciegos, las tropas de élite Guardias de la Real Persona, el Gobierno, la Iglesia y la inactividad de la Diputación permanente de las Cortes. La victoria popular del 7 de Julio hizo necesaria la intervención exterior, de la Santa Alianza. Muchos liberales moderados se asustaron de las consecuencias mismas del triunfo del liberalismo, y juzgaron que de Francia - país que en definitiva se regía por una Carta - les vendría la ayuda necesaria para desembarazarse del pueblo, y no la terrible represión que inmediatamente se desató y de la cual, los que no pudieron marchar al exilio, fueron las primeras víctimas. El ajusticiamiento de Riego el 7 de Noviembre de 1823 es el mejor símbolo de esta época aciaga $\left({ }^{23}\right)$.

Los siguientes diez años del restablecido absolutismo, 1823-1833, se parecen en algún sentido al período anterior 1814-1820, lo que explica los intentos repetidos de volver por la violencia al régimen liberal. Pero la pasada aceptación de la Constitución por el Rey, el no restablecimiento en esta etapa de la Inquisición y acaso cierta frustración teocrática explican que también los ultrarrealistas fragüen continuas conspiraciones para imponer su programa. Conjuras liberales y conjuras ultrarrealistas se suceden las unas a las otras hasta la muerte del rey en 1833. Acaso la primera es la intentada por el coronel Francisco Valdés que, partiendo de Gibraltar, el 3 de Agosto de 1824 se apoderó de Tarifa. Pensaba Valdés llegar hasta la Serranía de Ronda, pero la impaciencia de Cristóbal López Merino, quien al frente de unos paisanos proclamó la Constitución en Jimena, le obligó a acudir a defenderlo: unos días después absolutistas españoles y franceses le derrotaban. Valdés pudo escapar, pero el 24 de Agosto fueron fusilados en Algeciras treinta y uno de sus partidarios. Otros, separándose de Valdés, se habían dirigido hacia Almería, siendo también derrotados, con los consiguientes fusilamientos. Uno de ellos, el célebre Pablo Iglesias - no confundirlo con el socialista - fue conducido a Madrid, y ahorcado allí el 25 de Agosto de 1825 .

También en 1824 se descubrió en Cartagena una nueva conspiración, esta vez para favorecer un desembarco de emigrados. Las cosas no quedaron muy demostradas - más bien parece tratarse de una provocación ingeniada por el brigadiero realista Don Francisco Nebot, pero los conjurados fueron fusilados.

En Septiembre de 1824, por el contrario, se descubre la llamada Conjuración Carolina o de la Áncora o de la Estrella,

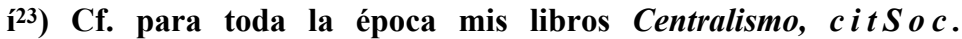
Pair.; y El Trienio liberal, Madrid, Siglo XXI, 1980. 
que trataba de proclamar a Carlos V, quitando a Fernando VII, por haber indultado S.M. a algunos liberales (sic), conjuración que se extiende por la Mancha, acaso Madrid, Aragón y otros puntos, y que debe estar en relación con la de los generales Capapé y Grimarest en Zaragoza. (Aunque esta conjuración se llama Carolina, ya en ella consta la palabra carlista, que muy pronto prevalecerá). Para el año siguiente las Juntas Apostólicas preparaban al parecer una insurrección general, pero sólo tuvo lugar la intentona de Bessiéres. Fracasado éste ante Sigüenza, el Conde de España lo hizo prisionero el 25 de Agosto de 1825 y lo fusiló al día siguiente, quemando sus papeles, para encubrir acaso más altas responsabilidades.

En 1826 aparecía el Manifiesto de la Federación de Realistas Puros, y a la vez el desembarco de los hermanos Fernández Bazán en Guardamar, cerca de Alicante, el 18 de Febrero de 1826. Perdida la acción de Muchamiel el 22, pocos días después fueron fusilados en Alicante y Orihuela. Los intentos liberales tienen siempre este aire de impreparación, que sólo sirve aparentemente para obligar al absolutismo a cubrise de sangre, y por tanto para su desprestigio. A este género pertenecen también la conspiración descubierta, o que se alegó haber descubierto en Canillas de Aceituno, cerca de Vélez Málaga - Enero de 1827 - y la del Coronel Don Miguel Nogueras, en Sariñena (Huesca) el 2 de Mayo de 1827: ambas terminadas en fracaso y ejecución.

1827 es también la fecha de la llamada Guerra de los Agraviados - els Malcontents —, con dos fases: una primera en primavera, superficial porque no fue seguida, pedía Inquisición, aplastamiento de los liberales, y cambio de Fernando por Carlos; la segunda, en el verano, con el mismo programa, excepto en lo relativo al destronamiento de Fernando VII, cobró enorme fuerza, con ciudades importantes, como Manresa, Vic, Olot y Cervera en poder de los insurrectos, y con la formación en Manresa de una Junta superior provisional de gobierno. Barcelona misma estaba amenazada. Fernando VII aplastó el movimiento, trasladándose él mismo a Cataluña $\left({ }^{24}\right)$.

La muerte de Juan VI de Portugal inaugura la crisis constitucional de este país - Don Miguel, reaccionario, contra Doña María de la Gloria, niña de corta edad - despertando las esperanzas de los emigrados españoles, que en 1827 intentan sin éxito aprovecharse de la coyuntura portuguesa para sus propósitos en España. Todavía mayor esperanza va a despertar la

(M) Cf. Jaime Torras Elias, La guerra de los Agraviados, Univ. de Barcelona, 1967. 


\section{Revueltas y Revoluciones en España}

revolución francesa de 1830 y las europeas en general de este año. Para estas fechas ya toda España se había cubierto otra vez de Juntas clandestinas, más o menos autónomas, en relación siempre y en dependencia muchas veces mal consentida de los emigrados. Pero hay que advertir que revolucionarios del interior y del exterior se hallaban en todo momento con infiltrados absolutistas, que por otra parte dejaban correr rumores falsos, por lo que era muy difícil para aquellos liberales saber quién era amigo y quién enemigo. Así tiene lugar el intento de invasión de España por la frontera de Navarra y Aragón - la expedición de Vera - en 1830. Fracasó, lo mismo que los intentos de Cataluña y Galicia. En Febrero de 1831 Torrijos desembarca cerca de Algeciras, teniendo que reembarcar inmediatamente. Salvador Manzanares pagó con su vida un intento semejante el propio año. En combinación con su acción llegó a darse una sublevación en Cádiz, pero fue prontamente traicionada y vencida. Finalmente Torrijos fue atraído a una auténtica emboscada desde Gibraltar a Málaga, y fusilado con sus compañeros sin proceso.

Todavía en Marzo de 1831 un espía denunciaba la llamada conspiración de Marco-Artu, eco de las actividades de Espoz y Mina. En 1832 seguían los fusilamientos. Al año siguiente murió el rey. Asombra en la etapa fernandina el número de conjuraciones e intentonas revolucionarias, asombra también la división mortal de los liberales desde el principio hasta el fin, cómo después de cada fracaso — ahogado en sangre — siguen conspirando, para ser delatados una vez más por el supuesto amigo. Esto parece demostrar que el absolutismo se mantiene por inercia, más que por pujanza propia, pero la forma de hacerse el intento revolucionario a lo largo de tantos años explica que a la muerte de Fernando VII el liberalismo no implique una profunda revolución social $\left({ }^{25}\right)$ -

Mientras comienza la primera guerra carlista (1833-1839-40), un nuevo período revolucionario se abre en la España que sigue a la reina niña Isabel, y que por comodidad llamaremos liberal. El miedo al carlismo explica muchos de los sucesos de estos años, aunque no lo explica todo. El sistema político llamado * 16

(") Cf. sobre las conspiraciones de este período mis artículos «La contrarrevolución fernandina (1814-1820 y 1823-1833)», Historia 16, extra III, Junio 1977, pp. 7-26, y «Repercusiones españolas de la Revolución de 1830», Anales de Literatura española, Universidad de Alicante, n. ${ }^{\circ}$ 2, 1983, pp. 281-328. Cf. también Irene Castells Oliván, «Torrijos y Málaga», Jábega, Málaga, 1982. El contexto europeo en Clive H. Church: Europe in 1830, London, George Allen \& Unwin, 1983. Del mismo: «Success and failure in 1830», Trienio, 2, Nov. 1983, pp. 41-72. 


\section{Revoltas e Revoluções}

del despotismo ilustrado no contenta a nadie, por lo que en Abril de 1834 es sustituido por el Estatuto Real, especie de carta otorgada con dos cámaras. Bajo su vigencia ocurren en España sucesos muy dramáticos, a través de los cuales la burguesía se hace con el poder.

La aparición del cólera morbo en Madrid - Julio de $1834\left({ }^{26}\right)$ - hace correr la especie de que los frailes habían envenenado las aguas, y de aquí la matanza de los mismos, típica estampa que todavía será recordada en 1931 (27). Digamos de paso que la situación económica de muchos conventos, las deserciones debidas a la guerra y a los pasados disturbios y las matanzas que empiezan en 1834 van a hacer posible la desamortización, realidad social antes que legal. Unos días después del degüello de los frailes se descubre la conspiración llamada la Isabelina, en la que aparecen comprometidos importantes personajes desde el general Palafox hasta el anciano Romero Alpuente - a éste la prisión le costará la vida - pero en la que no se sabe dónde acaba la verdad y donde empieza la suposición alarmista del Gobierno, acaso para desembarazarse de posibles críticos. Joaquín María López, procurador en las Cortes del Estatuto, se refirió a «esa conspiración, que más bien puede llamarse ridicula farsa» (28). Todo había partido al parecer de Eugenio de Aviraneta, fundador de una sociedad secreta titulada Los guardadores de la inocencia o Isabelinos, cuyos Estatutos imprimió. De acuerdo con Don Juan Olavarría y con otros liberales, dirigió una Exposición a la reina madre, sugiriéndole la conveniencia de cambiar el Estatuto Real por una Constitución inspirada en el modelo belga de 1830, menos radical que la del 12, pero todavía con disposiciones altamente revolucionarias.

En su intención lo que se pedía era perfectamente legal. Solamente si la reina se negaba a seguir el consejo se recurriría a la sublevación, con transformación del Estamento de procuradores en Asamblea Nacional y nombramiento de un gobierno. Después de esta agitación, todo quedó en agua de borrajas. Pero de nuevo la revolución estalló en 1835 y 1836.

Los acontecimientos de 1835 recorren rápidamente toda España, constituyendo la prolongación lógica de los movimientos

(M) Cf. Francisco Javier Puerto y Carlos San Juan, «La epidemia de cólera en 1834 en Madrid», Estudios de Historia Social, 15, Oct-Dic. 1980, pp. 9-63.

(27) Cf. Roberto Castrovido, La quema de conventos, en José M. ${ }^{a}$ de la Chica, Cómo se incendiaron los conventos de Madrid, Madrid, Edit. Castro, s.a. (1931), pp. 3-7. p. 199.

$\left.0^{\mathrm{a}}\right)$ Cf. Diario de las sesiones de Cortes, ${ }^{\circ}{ }^{\circ} 32,6$ Sept. 1834, 
de desobediencia cívica de 1821. Comienza con la acción del Ayudante Cardero contra la Casa de Correos de Madrid, de la que se apodera - 18 de Enero - y de cuyas resultas muere el general Canterac. Sigue un motín de subsistencias en Huesca, seguido de un alboroto en Málaga por haberse querido prohibir en la ciudad los cantos patrióticos. En Abril asesinato de frailes en Zaragoza, y en Murcia, y en Julio más asesinatos de religiosos en Zaragoza, bajo la influencia de la quema de conventos y matanza de frailes de Reus, de donde se corrió a Barcelona - asesinato del general Bassa el 5 de Agosto, y quema de conventos. En Barcelona la asonada adquiere un matiz luddita con quema de la fábrica El Vapor, lo que asustará a la burguesía. Nuevos desórdenes en Valencia, Murcia y Zaragoza. El Gobierno declara el estado de sitio en Madrid, y ordena la detención de varios procuradores. Entre Agosto y Septiembre pronunciamiento de Cádiz, Tarifa, Algeciras, Huelva, Málaga, Córdoba, Jaén, Granada, Sevilla, La Coruña y el Ferrol, Murcia, Badajoz y Cáceres, Asturias y Santander. El 14 de Septiembre de 1835 la reina llamaba a formar gobierno a Mendizábal, quien rápidamente fue logrando la pacificación. Sólo en Valencia hubo todavía una nueva conmoción, contra el jefe político, culpable de tibieza frente a la facción.

Más difícil se presentaba aparentemente la situación de Andalucía, en donde las diferentes Juntas habían organizado una Central, llamada de Andújar, por la plaza de su residencia, y un ejército que, al mando del Conde de las Navas, se dirigía contra Madrid. Pero la Junta de Andújar fue un órgano de corta duración - del 2 al 19 de Octubre de 1835 - tardío - ya que se constituye después del decreto de 28 de Septiembre de convocatoria de Cortes, que desarma al movimiento ciudadano, y finalmente entreguista, gracias a una negociación semisecreta en la que intervienen la Junta de Barcelona, interesada en yugular el movimiento andaluz, para concentrarse todos en la lucha contra el carlismo, Mendizábal, Istúriz y por la Junta de Andújar, Bartolomé Gutiérrez Acuña y Pedro Antonio de Acuña, además del Conde de las Navas. Intervienen también Argüelles y Alcalá Galiano ${ }^{(29)}$.

El movimiento revolucionario resurge en 1836 como consecuencia de que el 15 de Mayo María Cristina sustituye a Mendizábal por Francisco Javier Istúriz, antiguo exaltado súbitamente convertido al moderantismo - al decir de los autores pero a quien hemos visto en secreta combinación con el propio

$\left.C^{\circ}\right)$ Cf. mi art. «El movimiento juntero de 1835 en Andalucía», Cuadernos de Filología, Universidad de Valencia, III, 3, 1983, pp. 85-118. 
Mendizábal. Esta vez la insurrección comenzó en Málaga y se corrió a toda Andalucía, siguió luego a Zaragoza y Barcelona, estalló en Madrid el 3 de Agosto y culminó en el llamado Motín de los sargentos de La Granja, quienes el 13 de Agosto obligaron a S.M. a restablecer la Constitución de 1812.

Los movimientos de 1836 ofrecen agudas contradicciones, en las que no entraré ahora ${ }^{30}$ ). Baste decir que de ellos salió la convocatoria de Cortes constituyentes, que redactaron la Constitución de 1837; Constitución derivada de un pacto entre progresistas y moderados, que no recoge las aspiraciones populares, y desde el punto de vista de la revolución burguesa, aunque equivale a la asunción del poder por la burguesía, lo hace renunciando al mismo tiempo la burguesía a acaudillar el movimiento popular, y tolerando la perduración de muchos elementos del pasado feudal. Aun así esta Constitución pudo presentarse como «un hecho de civilización», frente al carlismo ( $\left.{ }^{31}\right)$.

Típica del momento político que se vivía en España en vísperas de la promulgación de la Constitución de 1837, fue la «soñada conspiración de Noviembre de 1836», tan parecida a la Isabelina: se habla de reuniones de elementos liberales, pero lo efectivo fue la detención de una serie de prohombres que habían manifestado inclinaciones demócratas, como Benito Alejo Gaminde, Lorenzo Calvo de Rozas, José María Orense y otros ( 32 ).

Es lógico pensar que Larra se suicidase (1837), aunque alguno de los periódicos que mantienen la llama revolucionaria se lo censure (33). Desde 1837 hasta el final de la primera guerra carlista, 1839 en el frente vascongado y 1840 en el catalán, no encontramos más movimientos - aparte los carlistas - que indisciplina en el ejército, duramente reprimida por Espartero, y la pugna entre éste y Narváez por el dominio militar - y político - en España ${ }^{34}$ ). Los generales Luis Fernández de Cór-

(30) Cf. mi art. «El problema de la revolución en el liberalismo español (1808-1868), Estudios de Historia Social, 22-23, Julio-Dic. 1982, pp. 7-22.

(31) Cf. el cap. V «Liberalism and Carlism» de Raymond Carr, Spain 1808-1939, Oxford, Clarendon Press, 1966.

(32) Cf. El Duende liberal, Madrid, N. $\circ 2,19$ Nov. 1836, y números siguientes hasta el 232, 13 Mayo 1837. 'Y El Matamoscas, Madrid, cit. en nota siguiente.

(33) Cf. mi art., «Prensa satírica de la época de Larra: El Matamoscas", en Albert Dérozier (ed.), Revisión de Larra, París, Les Belles Lettres, 1983, pp. 133-140.

${ }^{(34)}$ Cf. Luis Bordas, Historia de la revolución y guerra civil de España, Barcelona, Imp. Hispana, 1847, p. 302 y ss. Ramón María Narváez, Manifiesto del Mariscal de Campo... en contestación a las acusaciones del Capitán General Conde de Luchana, Madrid, Imp. Comp. Tipográfica, 1839. 
doba y Narváez trataron de ponerse en Sevilla al frente de una Junta contrarrevolucionaria, Noviembre 1838, pero fracasados tuvieron que salir de España (35). Es interesante, sin embargo, señalar ya en esta época la presencia de intentos revolucionarios, de tipo republicano, muy mal conocidos, como los de los subtenientes Doti y Guisasola en León, Enero de 1838: ambos fueron prontamente fusilados $\left({ }^{36}\right)$.

En 1840 se produce la llamada revolución de este año, triunfo de Espartero sobre María Cristina, con la marcha de ésta a Francia y la exaltación de aquél a la Regencia. Frente a los proyectos retrógrados de María Cristina - ley municipal, etc. - y frente a los hombres del llamado «partido jovellanista» - miembros de la Sociedad jovellánica, continuadora de la del Anillo — se levantaron los liberales en Septiembre de 1840 , y le dieron la victoria a Espartero ( ${ }^{37}$ ). Existe ya en esta época un intenso movimiento popular, del mejor estilo zurriaguesco de antaño, que es frenado y perseguido por el poder oficial, y tampoco prospera un movimiento de Juntas

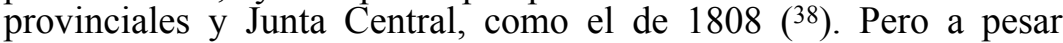
de esta moderación del poder, empiezan en seguida las sublevaciones, que la política desacertada del Regente va a intensificar.

Aduciendo como pretexto que el partido moderado no reconocía más legalidad que la de María Cristina, se praparó una contrarrevolución para 1841, a cargo de Diego de León y otros en Madrid, Leopoldo O'Donnell en Pamplona, Borso di Carminati en Zaragoza, Narváez en Andalucía, y Montes de Oca en las Provincias Vascongadas. De todos los comprometidos, el único que tuvo cierto éxito fue O'Donnell. Los demás pagaron con su vida el intento, excepto Narváez, que no se movió de Gibraltar, es decir, no acudió a sublevar Andalucía ${ }^{\left({ }^{39}\right) \text {. }}$

Todo esto repercutió en Barcelona, donde comenzó a derribarse la Ciudadela, para evitar que se repitan en la Ciudad Condal las escenas de Pamplona, con un muy notable matiz foralista, contra Felipe V, pero donde comenzaron a ser desarmados con cierta alarma estudiantes y jornaleros, descamisados

(36) Cf. Exposición de los sucesos de Sevilla en el mes de Noviembre de 1838, Sevilla, Imp. de D. J. H. Dávila, 1839.

$\left({ }^{3}\right.$ «) Cf. Fray Gerundio, Léon, $4 .^{\circ}$ Trimestre, 1838, pp. $72-94$.

(3T) Cf .Reseña histórica del glorioso alzamiento de 1840, Madrid, Imp. de Vicente de Lalama, 1840.

C) Cf. Enrique Rodríguez Solís, Historia del partido republicano español, Madrid, Imp. de Fernando Cano y Domingo del Val, 1892-93, II, pp. 376-77; J. A. González Casanova, Fédéralisme i autonomía à Catalunya, Barcelona, Curial, 1974.

(39) Cf. Carlos Navarro y Rodrigo, O'Donnel y su tiempo, Madrid, Imp. de. la Biblioteca Universal Económica, 1869, pp. 53-55. 
y anarquistas, partidarios todos ellos de Espartero el año anterior ${ }^{(40)}$.

En Noviembre de 1842 Barcelona volvió a inflamarse contra el Regente, con participación obrera y republicana, y cierto matiz anti-militar (41) que derivó en una Junta Popular Directiva, que contó con amplio apoyo social, y que pedía descentralización, proteccionismo y reforma liberal del Estado ( ${ }^{42}$ ). La torpeza de Espartero consistió en no haber encontrado otra respuesta que la de bombardear la ciudad. Se puede decir que éste fue el principio del fin de su Regencia.

Al año siguiente, en efecto, moderados y progresistas catalanes se unen al movimiento generalizado en toda España contra Espartero, movimiento centralista, es decir, propugnador de una Junta Central a partir de las Provinciales, al estilo de 1808, contra el progresismo anglofilo y centralizador del Regente. Aunque en la España de entonces había una gran variedad de pensamiento político radical - comuneros, isabelinos, federalistas, carbonarios, al decir de Tanski $\left({ }^{43}\right)$ - bastó la acción solidaria promovida por el Eco del Comercio para defender la libertad de imprenta - 25 Octubre 1843 - para congregar en la oposición al gobierno a moderados y progresistas, y a que, mediante la victoria militar de Narváez, oportunamente desembarcado en Valencia, el glorioso movimiento nacional de 1843 se transformase en una fecha más de las que marcaron la contrarrevolución en España. A los progresistas, por apocados, se la jugaron los moderados. También es normal en nuestra Historia. En este rápido desarrollo de los acontecimientos Zaragoza, Valencia y Sevilla ocupan, junto a Barcelona, un puesto esencial $\left({ }^{44}\right)$

Espartero perdió la Regencia, y la reina, inconstitucionalmente, fue proclamada mayor de edad. Olózaga tuvo que huir de España. Mientras tanto comenzaban las persecuciones. Dos- $\left.{ }^{*}{ }^{* *}\right)$

(40) Cf. Manifiesto de la Milicia Nacional armada de Barcelona, Barcelona, Imp. del Constitucional, 1841.

(41) Cf. Manuel J. Risques, «La insurrecció de Barcelona pel novembre de 1842. La seva dinâmica social», Recerques, 10, 1980, pp. 93-112. 1844.

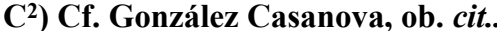

$\left.i^{* 3}\right)$ Cf. J. Tanski, U Espagne en 1843 et 1844, París, A. René,

(**) Cf. Joaquín María López, Exposición razonada de los principales sucesos politicos que tuvieron lugar en España durante el Ministerio de 9 de mayo de 1843, y después en el Gobierno provisional, Madrid, José M.a Canalejas, s. a. Raymond Carr, Spain 1808-1939, Oxford at the Clarendon Press, 1966, pp. 224-27. José Amador de los Ríos, Alzamiento y defensa de Sevilla, Sevilla, Alvarez y Cía, 1843. 
cientos republicanos sevillanos se apoderaron de Morón, pero batidos en Benamejí, fueron pasados por las armas. Lo mismo ocurrió con otros que se alzaron en La Carolina ${ }^{45}$ ). Ya con régimen oficialmente liberal comenzaba la larga queja de los hombres sensibles, de los amantes de la Libertad, como en las mejores épocas absolutistas. La Guardia Civil se creó en 1844. Incluso las exhalaciones inocentemente poéticas se vieron perseguidas ${ }^{46}$ ). Esta política moderada, con exclusión total de los progresistas, determinará el destronamiento de Isabel II en 1868. Pero para llegar a esta fecha en algún sentido grande, todavía habrá que pasar por la revolución de 1854 y los diversos movimientos que la prepararon.

Inspirándose en el levantamiento de Septiembre de 1840 y contra la ley de Ayuntamientos repuesta inmediatamente por el Gobierno reaccionario, se levantó Don Pantaleón Bonet en Alicante, seguido al poco de la formación de una Junta en Cartagena $\left({ }^{47}\right)$. Pero fueron en seguida desbaratados. Bonet, ex-carlista pasado a Espartero, pagó con su vida $\left({ }^{48}\right)$. Esto no es nuevo, pero sí lo fue que el gobierno cobró miedo, veía por todas partes partidarios de la Junta Central, y de hecho, auque no de derecho, puso fuera de la ley al partido progresista, ya que consideraba instigadores de la revolución a Pascual Madoz y a su hermano Fernando, Manuel Cortina, Joaquín Garrido, Juan Antonio Garnica, Joaquín María López, Miguel Ors y García, Joaquín Verdú y Pérez, Marnés Benedicto, el Marqués de Tabuérniga, Ramón Calatrava, Becerra, Caballero, Velo, etc., $>$ al obispo electo de Jaén $\left.{ }^{49}\right)$. A todos ellos se les formó pro- ${ }^{*}{ }^{* *}$

05) Cf. Mario Méndez Be jarano: Idealismo jurídico-politic o $e$ historia interna de la Revolución de Septiembre de 1868, Madrid, Real Acad. de Jurisprudencia y Legislación, 1919², p. 10.

(4fi) Cf. José Ordás y Avecilla, Defensa verbal que el abogado... pronunció en el Jurado celebrado el veinte y seis de junio del presente año, para calificar el folleto titulado Proscriptos y encarcelados, en Causas, cit., VI, pp. 345-376 (el folleto comprendía los siguientes cantos: La noche, de José Ferrer; La expatriación, de Julián Santín Quevedo; Recuerdos de la Patria, de Andrés Avelino Benitez; La libertad perdida, de Alfonso García Tejero; La esperanza, de Luis Díaz y Montes; Al sol de la libertad, de Braulio Antón Ramírez).

(4T) Cf. Evaristo Escalera y Manuel González Llana, La España del Siglo XIX, Madrid, J. J. Martinez, 1865, III, pp. 370-372.

(**) Cf. Tanski, ob. cit.

(4fl) Cf. Causa criminal... contra... D. Joaquín María López y D. Manuel Cortina y los señores D. Pascual Madoz, D. Juan Antonio Garnica, D. Miguel Ors y García, D. Joaquín Garrido, D. Joaquín Verdú y Pérez y D. Marnés Benedicto por sospechas de complicidad en el alzamiento de la ciudad de Alicante verificada en 28 de Enero de 1844, en Causas, VII, 1863, pp. 5-222. 
ceso, y aunque fueron absueltos, el efecto de considerar provisionalmente delincuente a toda actitud política no moderada se había conseguido. Esto recuerda viejos procedimientos de 1820. Se diría que nada había cambiado en España.

Sin embargo la revolución era necesaria, y la conducta a diario del poder acrecentaba esta necesidad. Así lo comprendió el general Don Martín Zurbano, quien en Noviembre de 1844 se pronunció en Nájera en favor de la Constitución de 1837: sólo le siguieron los pueblos de Hecho y Ansó, en el Pirineo aragonés, por lo que fueron todos prontamente vencidos. La ejecución de Zurbano se hizo célebre en los anales de España $\left.{ }^{50}\right)$. Esta situación, más la aprobación en 1845 de la reforma tributaria de Mon, determinó el estallido de la revolución gallega de 1846, llamada de «los mártires del Carral», por el destino que tuvieron sus protagonistas: ser fusilados en el pueblecito de Carral. Iniciada la sublevación en Lugo por el coronel Miguel Solís y Cuetos a los gritos de ¡Viva la libertad! ¡Viva la Reina libre y constitucional! ¡Abajo la camarilla y el dictador Narváez! ¡Abajo el sistema tributario!, se pronunciaron sucesivamente las ciudades de Santiago — con sus estudiantes Pontevedra y Vigo, formándose una Junta Suprema del Reino de Galicia. Esta es la primera vez que empiezan a notarse ciertas tendencias galleguistas, ejemplificadas en la persona de Antolín Faraldo, director del periódico La revolución. Solís se comportó en su sublevación con una caballerosidad, que recuerda la de Riego en 1820. El premio ya se ha dicho: sorprende en efecto la vesania con que los sublevados de 1843 fusilan a los que contra su violación del derecho se sublevan posteriormente $\left({ }^{51}\right)$.

Todavía en esta época se señala la existencia de motines del pan, como el de Sevilla de 6 de Mayo de 1847, motín que dio lugar, como era sólito, a que el jefe político resignase su poder en el capitán general, quien curándose en salud prohibe la salida antes de la hora acostumbrada de los obreros de la fábrica de tabacos (52). También en La Coruña, 20 y 25 de Marzo de 1847: oposición al embarque de maíz; Granada, 4 Mayo 1847, provocado por el precio del pan $\left({ }^{53}\right)$, etc. Esta situa-

(60) Cf. Eduardo Chao, Historia de la vida militar y política de Martín Zurbano, Madrid, Est. lit-tip. de P. Madoz y L. Sagasti, 1846. Fernando Garrido, Historia del reinado del último Borbón de España, Barcelona, S. Mañero, 1868-69, II, pp. 604-606.

(») cf. Francisco Tettamancy Gastón, La revolución gallega de 1846, La Coruña, Imp. y Fotograbado de Ferrer, 1909². Mayo 1847.

${ }_{\left({ }^{2}\right)}$ Cf. Diario de Sevilla de Comercio, Artes y Literatura, 8

(") Cf. Archivo Militar General de Segovia, Sección 2..$^{\circ}$ Div. 4. ${ }^{\circ}$, Leg. 197. 


\section{Revueltas y Revoluciones en España}

ción explica la aparición de partidas carlistas, autorizadas a la rebelión por el fracaso, público ya en 1845, de los planes matrimoniales entre Montemolín (Carlos VII) e Isabel II. Las partidas aparecen en Cataluña (Berga), y por lo menos La Mancha y Andalucía. Fenómeno interesante es la colaboración entre carlistas y republicanos, motivada a mi juicio por la guerra sin cuartel a que se entregan las fuerzas del orden, con frecuente utilización de la que más tarde se llamó ley de fugas. Aun así, no deja de ser políticamente sorprendente la formación de la llamada conspiración carlo-republicana en torno de Cabrera.

Aunque Montemolín ya el 12 de Septiembre de 1846 dio un manifiesto en el que dice que los resultados de la acción carlista no han sido como se esperaba, y en consecuencia predica concordia entre los españoles, las causas de fondo de la insurrección la prolongan hasta enlazar con la revolución francesa de 1848. La vigilancia de Narváez logró impedir en España una fuerte participación revolucionaria, pero aun así hubo conatos en Huesca (Manuel Abad), Madrid y Sevilla, además de Cataluña. Montemolinistas hubo también en Navarra y en el País Vasco, pero a finales de 1848 el movimiento está terminando en todas partes. Algunos motines militares - Sevilla, Diciembre 1848 - indican que la inquietud se ha comunicado también a las fuerzas armadas $\left({ }^{54}\right)$.

Lo que en 1848 no pudo lograrse, se realizará unos años después, ya que existe en todo el país una sorda oposición al moderantismo; hay una perenne actitud de expectativa, que busca el desquite. Conocemos la existencia de alguna Junta revolucionaria en 1853, como la de Cataluña, compuesta de progresistas avanzados y demócratas republicanos (55). Pero la revolución va a comenzar bajo la forma clásica de un pronunciamiento militar, protagonizado por los generales O'Donnell y Dulce.

La política de los llamados ministros de Palacio, los proyectos de revisión constitucional — inspirados en parte por el éxito de Napoleón III en 1851 - y las concesiones ferroviarias dieron lugar a una situación de molestia de unos cuantos capitalistas y militares, preteridos en las preferencias gubernamentales; los cuales, frente a la persecución de que les hizo objeto el Conde de San Luis buscaron novelescamente el camino para

(M) Id., id., leg. 196. Cf. también Teatro de la guerra: Cabrera, los montemolinistas y republicanos en Cataluña, Madrid, B. González, 1849, y Joan Camps i Giró, La guerra deis matiners $i$ el catalanisme politic (1846-1849), Barcelona, Curial, 1978.

(X) Qjp Francisco Rispa y Perpiña, Cincuenta años de cons pirador, Barcelona, Librería Villella, 1932, pp. 7-8. 


\section{Revoltas e Revoluções}

alzarse (56). En un primer momento la cosa no pasaba de ser, por tanto, una revuelta de privilegiados. El pronunciamiento de Leopoldo O'Donnell — 28 Junio 1854 - corría peligro de agotarse en sí mismo, ante la indiferencia general. La conciencia de la situación en que se encontraba le obligó a dar el famoso Manifiesto de Manzanares — 6 de Julio _, redactado por Antonio Cánovas del Castillo, el futuro cabecilla de la Restauración. El Manifiesto contenía promesas de moralidad pública y buen gobierno y el restablecimento de la Milicia Nacional. Por él la revuelta se transformó en revolución: Barcelona, Valencia, San Sebastián, Valladolid y en Madrid mismo tuvo lugar la célebre revolución de Julio. No voy a entrar en la discusión sobre si el hecho decisivo de la revolución hay que ponerlo en Madrid o en provincias (57).

Lo que sí es evidente es la continuidad que esta serie de revoluciones tienen con los momentos revolucionarios anteriores del pueblo español. Es el espíritu de 1820 y de 1835-36, y de 1840-1848. Todavía el 7 de Julio el Ministro de la Guerra, Anselmo Blaser, para acabar con el alzamiento, ofrecía el perdón de la Reina a los sublevados. Unos días después el pronunciamiento de la división que mandaba el propio Blaser dio al traste con toda resistencia. Nada indica mejor el ánimo de la insurrección que el siguiente fragmento de carta de la Junta Popular de Gobierno de Pozoblanco:

«Once años hace que día por día están anhelando los que tienen la honra de componer esta Junta Popular, el triunfo de la libertad, la libertad de la Patria y la reparación de sus inmensas pérdidas desde el año del 43 . Once años de esclavitud, de persecuciones, de amargura y conflictos han desaparecido como en fugaz meteoro...» (57a).

ante el triunfo de Espartero y San Miguel. Estos nombres, fantasmas del pasado, como decía Marx $\left({ }^{58}\right)$, eran el producto de

(") Cf. V. G. Kiernan, The Revolution of 1854 in Spanish History, Oxford, At the Clarendon Press, 1966. Angel Fernández de los Ríos, Estudio histórico de las luchas políticas en la España del siglo XIX, Madrid, English y Gras, 1880, 2.a ed., II, p. 331 y ss.

(5T) Cf. Marie-Claude Lecuyer, «Los pronunciamientos de 1854», Estudios de Historia Social, 18-19, Julio-Dic. 1981; id.: «La formación de las Juntas en la revolución de 1854», id., pp. 22-23, julio-dic. 1982. José Ramón Urquijo y Goitía, La revolución de 1854 en Madrid, Madrid, CSIC, 1984.

(era) Archivo General Militar de Segovia, Sección 2.a, Leg. 198. En adelante AGM Segovia.

(") Cf. Karl Marx - Friedrich Engels, Revolución en España, Caracas-Barcelona, Ariel, 1960 (trad, de Manuel Entenza), p. 37, en donde la frase «ilusiones del pasado» se aplica a Espartero. 


\section{Revueltas y Revoluciones en España}

la revolución en provincias, especialmente en Aragón, y en Madrid. Interesante tema, que aquí no podemos ni tocar, es el de la conducta ante la revolución de la guardia civil, que sólo contaba diez años de vida $\left(^{59}\right)$. Llama la atención, entre los telegramas que envían las Juntas revolucionarias, la mención de que reina la más completa tranquilidad, lo que parece indicar que los elementos de orden dominan y encauzan las fuerzas populares $\left({ }^{60}\right)$.

Esto es justamente lo que pasó en Madrid, en donde la revuelta popular dio lugar a la formación de Juntas, como la llamada del Sur, con fuerte acento demócrata: frente a ella la Junta de Salvación, Armamento y Defensa, constituida por San Miguel, no tenía más finalidad que salvar a la Monarquía, evitando los aspectos más peligrosos de la revolución. La solución estaba en Espartero y O'Donnell a la vez. Pero es sintomático que mientras O'Donnell camino de Madrid pregunta por telegrama el 24 de Julio si ya ha llegado Espartero, éste informa el 28 desde Guadalajara que viene bastante fatigado, por lo que hasta el día siguiente no saldrá de Alcalá (61).

Así dio comienzo el llamado Bienio progresista, que termina en 1856 con la eliminación de Espartero del Gobierno. Durante este tiempo todavía más abiertamente de como lo hiciera en épocas pasadas, el Trono conspira contra la revolución, se convocan unas Cortes constituyentes, redactoras de una Constitución que no llegará a regir, se promulga una nueva ley desamortizadora, que dará lugar a conflictos con la Iglesia, se asiste a una nueva rebelión carlista y hay una intensa agitación popular $\left({ }^{62}\right)$. Los problemas sociales dieron lugar en Barcelona a una gran actividad luddita, contra las selfactinas, a su prohibición y reposición alternativa por la autoridad, al comienzo de una gran represión en la que se fusiló al líder obrero Josep

O Siempre al servicio del Gobierno, según Alfredo Opisso, La Guardia Civil y su tiempo, Barcelona, s.a., I, p. 80.

$O$ Así p. ej. la Junta de Cádiz comunica su instalación el 22 de Julio en los siguientes términos: "Cádiz se ha adherido al alzamiento nacional. Se ha constituido una Junta. Ningún servicio público se ha interrumpido, y continúa reinando la más completa tranquilidad» (AGM, Sección 2. a, Leg. 198); estos legajos han sido trasladados al Servicio histórico militar de Madrid, conservando las signaturas de Segovia).

(w) Cf. AGM Segovia, Legs. 198.

(82) Cf. Kiernan, ob. cit. Antonio Ignacio Cervera, La voluntad nacional. Como el pueblo espera que la interpreten las Cortes Constituyentes, Madrid, lmp. de Tomás Núñez Amor, 1854 (reproducido por Antonio Elorza en Estudios de Historia Social, 10-11, Julio-Dic. 1979, pp. 432-444). 
Barceló, y finalmente en Julio de 1855, siempre en Barcelona, al desencadenamiento de la primera huelga general de España ${ }^{65}$ ). Las ideas socialistas utópicas cundían por el país.

En 1856 la situación social, incluso campesina, se agravó. Sequía y escasez dieron lugar a motines del hambre, pronto reprimidos. En este ambiente de «peligro rojo», un tanto exagerado, se produjo la sustitución de Espartero por O'Donnell, es decir la contrarrevolución, frente a la cual la resistencia que opusieron las clases populares en el mismo Madrid fue notable - Sixto Cámara se encontraba allí - Hubo también alguna resistencia en Galicia, y sobre todo en Andalucía, y una vez más en Barcelona, en donde la situación llegó a ser muy seria, y otras ciudades de Cataluña (64). La represión fue durísima (65).

Todavía intentó Sixto Cámara, escapado de Madrid, la resistencia en Málaga, Noviembre de 1856, con Romualdo de Lafuente, Bernardo García y otros, y en Zaragoza, mediante la creación en Abril de 1857 de la Junta Nacional Revolucionaria, en cuyo manifiesto dice no querer

«abandonar al pueblo a la funesta dominación de los once años; a aquella dominación que por abajo difundía ${ }^{\wedge}$ el terror y la miseria y por arriba se formulaba en escándalos y orgías» $\left({ }^{€ C}\right)$.

La citada Junta de Zaragoza formaba parte, probablemente, de la Nueva Carbonaria, vasta conspiración revolucionaria dirigida desde Portugal por Eladio Manuel Guerra, quien suele firmar «Yo soy el que soy», y Sixto Cámara, aunque éste no parece haber llevado los hilos de la trama. De Marzo a Mayo de 1857 se extiende esta conspiración demócrata, con aspectos muy arcaicos - la traducción como arma de lucha de un libro

(M) Cf. Josep Benet i Casimir Martí, Barcelona a mit jan segle XIX. El movimiento obrer durant el bieni progressista (1854-1856), Barcelona, Curial, 1976, dos vols.

(M) Cf. Ramón Garrabou, «Un testimonio de la crisis de subsistencia de 1856-57: el expediente de la Dirección General de Comercio», Agricultura y Sociedad, 14, Enero-Marzo 1980. Benet i Martí, ob. cit., Kiernan, ob. cit..

(w) Cf. Alberto Columbrí, Memorias de un presidiario político (1857), Barcelona, Imp. Española de I. López, 1864. Rafael Pérez del Alamo: Apuntes sobre dos revoluciones andaluzas. Introducción de Antonio María Calero, Madrid, Zero, 1971, p. 51 (desarme de la MN de Lo ja, la patria de Narváez y de Pérez del Alamo).

O Cf. Sixto Cámara, La Junta Nacional Revolucionaria al Pueblo. Zaragoza y Abril de 1857 (hoja suelta, sin pie de imprenta, existente en la BN de París, Oc 1323), Fernando Garrido, «Sixto Cámara», Obras escogidas, Barcelona, Salvador Mañero 1859, I, pp. 389-420 . 
sobre Paralelo entre Jesucristo y los Papas, por ejemplo - con voluntad de exterminio de toda la familia real española y de todas las autoridades de Madrid, pero también dando entrada en la conspiración a las organizaciones obreras, de hiladores y tejedores - al hablar de ellos, sin embargo, se piensa en la Inglaterra de Carlos I - y lo mismo que en las vísperas de 1848 se acepta la colaboración, como hermanos, de republicanos y carlistas. La finalidad es la liberación del pueblo y la regeneración de toda la humanidad. En muchas cartas se repite la frase de que

«La justicia nacional castigará a todos los traidores, a todos los tiranos del pueblo, a todos los opresores de la humanidad».

Se fijó el día de la ruptura en el 10 de Mayo de 1857, pero como todos los documentos ultrasecretos - ingenuidad de los revolucionarios - habían caído en manos del Gobierno, fue fácil desbaratarla. El resultado fue un centenar de fusilamientos y un millar de deportaciones ${ }^{(67)}$.

Yo no sé si en este cómputo entra la represión de las gavillas aparecidas en Andalucía en el verano de 1857. Como decía un jefe de la Guardia Civil de Sevilla, «el partido republicano es aquí socialista». Circulan proclamas impresas sobre la Milicia (Nacional), sobre libertad de imprenta. Se temen los ataques a la propiedad en la forma de incendios y robos. De hecho a finales de Junio de 1857 apareció en Utrera, Pruna, Arahal, Paradas, etc., una facción de 120 o 150 hombres, capitaneados por D. Manuel Caro, comandante expulsado del ejército por la reacción de 1845 , partida que difunde el grito de «Viva la República, mueran las quintas y los consumos». Típico del movimiento es que a él se sumaron los obreros del ferrocarril y los segadores de Puente Genii. Después se dijo que el motín de Arahal era comunista.

La represión fue feroz. El ejército les persiguió y derrotó, e incluso en algún comunicado oficial se habla de que los habitantes de los pueblos colaboraron a la derrota de los revolucionarios; pero habría que saber de qué clase de habitantes se trata. Los principales jefes, Manuel Caro, Gabriel Lallave, Rafael Latorre, fueron inmediatamente fusilados, lo mismo que Antonio Romero, alias «el Buñolero», y otros muchos. Las eje-

$\left({ }^{\mathrm{T}}\right)$ Cf. Pedro de Répide, «Un conspirador de ayer», en Los espejos de Clio, Madrid, Edit. América, s.a., pp, 107-152. Y AGM de Segovia (ahora en Madrid), Leg. 175. Pierre de Luz, Isabel II reina de España, Barcelona, Juventud, 1937, p. 202. 
cudones se sucedieron desde el 8 de Julio hasta el 15, en cuya fecha se dio la orden de que siga en sus tareas la Comisión militar, pero que no se mate a nadie antes de consultar con

S.M., por si tiene a bien ejercer la regia prerrogativa. A esta orden tardía se había llegado como consecuencia de las peticiones de indulto de Sevilla, de 13 de Julio de 1857, que todavía hoy nos impresionan: implora misericordia el pueblo sevillano (95 páginas de firmas), la Asociación de Beneficencia Domiciliaria de la capital - vicepresidenta, la Marquesa Viuda de la Motilla; secretaria general, la Marquesa del Moscoso - y el propio Ayuntamiento de Sevilla.

Además de las ejecuciones, hay que contar las deportaciones, muchos enviados al Penal de Ceuta y al correccional de Badajoz, «a fin de alejarlos del trato y relaciones que pudieram tener con sus respectivas familias» (sic). A algunos, como al capitán general de Andalucía Atanasio Aleson, no les parece esto suficiente. Aleson solicita del Gobierno que, después de que se haya cumplido la ley en todo su rigor, se le permita mandar al servicio de las armas en Ultramar a los jóvenes de los pueblos que hubiesen simpatizado con la rebelión. El Gobierno lo pensó acaso mejor y sustituyó a Aleson por Manuel Lassala y Solera, quien el 19 de Julio dio un manifiesto en el que decía que el ejército ha sido, y será, «la tabla salvadora del trono, de las instituciones y del orden», y anunciando también que a partir de ese día cesan las penas de muerte ${ }^{88}$ ).

En Marzo y Abril de 1860 tuvo lugar una intentona carlista, con el coronel Jaime Ortega en San Carlos de la Rápita. Fácilmente vencido, Ortega fue ajusticiado, mientras el pretendiente Montemotín huía en tartana ( $\left.{ }^{69}\right)$.

Con las insurrecciones andaluzas de 1857 hemos encontrado ya las famosas agitaciones de la región. Clásica fue la acaudillada en 1861 por Rafael Pérez del Alamo, el albéitar de Lo ja, quien había montado una conjura con ramificaciones en varios pueblos, Alhama, Loja, Antequera, Mollina, Iznájar y otros; pero la acción se precipitó por un decreto judicial de prisión contra Pérez del Alamo, al que respondió el 28 de Junio poniéndose a la cabeza de 600 hombres, luego aumentados a varios miles con los que tomó la villa de Iznájar y a continuación Loja, al grito de «Viva la República y muera la Reina».

(M) Cf. Manuel Lassala, Habitantes del Distrito Militar de Andalucía, Sevilla 19, Julio 1857 (bando impreso, en leg. 175 AGM Segovia). Maximiano García Venero, Historia de las Internacionales en España, Madrid, Eds. del Movimiento, 1956, I, pp. 51-52.

(fi9) Cf. Miguel Villalba Hervás, Recuerdos de cinco lustros 1843-1868, Madrid, La Guirnalda 1896, p. 197 ss. 
En Loja se hizo fuerte, y resistió el asedio hasta el 4 de Julio, en cuya fecha salieron de la ciudad en todo orden, dispersándose y poniéndose otra vez a trabajar en el campo. La ideología de Pérez del Alamo es republicana y anticlerical, con fuerte acento social, aunque no sea del todo exacto llamarle socialista. Todo lo más se ha visto alguna diferencia entre la actitud del líder y la de la masa que le sigue, ésta más radical acaso en todo. La represión no fue tan sangrienta como en 1857. Pero el susto, incluso entre los progresistas, fue enorme: Olózaga, en un famoso discurso del propio año 1861, no dudaba del carácter socialista de los sucesos de Loja, y lo que es peor, le parecía que toda España lo era, hasta hacerle temblar: incluso a la sopa de los conventos la reputaba propagadora del socialismo $\left({ }^{70}\right)$. También en Aragón en 1861 se persigue a los carbonarios, sin que podemos precisar la exactitud de la acusación $(\mathrm{n})$.

El susto no logró, sin embargo, la reconciliación de los partidos progresista y demócrata con la Monarquía. Isabel II corría hacia su destronamiento. En 1863 se produce el retraimiento de los progresistas, y la inútil apelación - aún es tiempo, Señora - de Carlos Rubio ( ${ }^{72}$ ). El general Prim, cuya historia no era precisamente la de un enamorado de la libertad, se distanció también de la Corona y pasó al extranjero, dispuesto a conspirar, tras haber brindado en Oviedo por la Virgen, por Don Pelayo y por el general Riego (73). Los años siguientes son, en gran parte, los de sus intentos revolucionarios, que culminarán en Septiembre de 1868.

En 1864, puesto al habla Prim con los demócratas, pudo formarse un directorio revolucionario y dos juntas, una progresista y otra demócrata. Se trabaja activamente en lograr adhesiones militares, puesto que en los planes de Prim y sus amigos el ejército lo era todo. La conspiración penetró profundamente en los medios militares, pero no se encontraba nadie

(70) Cf. Juan Díaz del Moral, Historia de las agitaciones campesinas andaluzas - Córdoba, Madrid, Alianza Edit., 1973, pp. 78-81. Rafael Pérez del Alamo, ob. cit., El discurso de Olózaga en La Iberia, Suplemento 19 Die. 1861. A. Gil Novales, "Las contradicciones de la revolución burguesa española», Coloquio Internacional de Leipzig, Nov. 1983 (en prensa).

(n) Cf. (Eduardo Ruiz Pons), Historia de la causa formada en Zaragoza el año de 1861 contra el Ex-constituyente ...y consortes..., Porto, Typographia de D. Antonio Moldes, 1864, pp. 19, 44, 132 y 135.

(T2) Cf. Carlos Rubio, «Reverente carta que dirige a S. M. la Reina D. a Isabel II», La Iberia, 12 Die. 1863. p. 385.

(T3) Qf Rafael Olivar Bertrand, Prim, Madrid, Tebas, 1975, 
que se atreviera a ser el primero, el tiempo pasaba entre la impaciencia de los conjurados. Así se llegó a la intentona del 6 de Junio de 1864, que fue un fracaso, y después a la del 5 de Agosto del mismo año, que fracasó también... antes de nacer $\left({ }^{74}\right)$.

Las dificultades en que se hallaba el Tesoro decidieron a Isabel II a autorizar la venta de una parte del Patrimonio Real, $75 \%$ para la nación, $25 \%$ para su presupuesto particular, lo que fue muy elogiado por toda la prensa moderada. Emilio Castelar replicó con su artículo «El rasgo», publicado en La Democracia, en el que satirizaba la supuesta generosidad de la reina. Narváez exigió al Rector de la Universidad de Madrid que lo expulsase de la cátedra, el Rector se negó, los estudiantes se manifestaron, la Guardia Civil ocupó la Universidad: en la noche de San Daniel, 10 Abril 1865, hubo nueve estudiantes muertos y más de cien heridos $\left({ }^{75}\right)$.

Más gravedad todavía revistieron los sucesos de 1866: sublevación en Aranjuez y Ocaña de los regimientos de caballería de Bailén y Ocaña, 3 Enero 1866, que se pusieron a las órdenes de Prim, sublevaciones militares también en Ávila y en Tarragona y en Béjar, aparición de una partida en Alhama de Aragón. El 22 de Junio tuvo lugar el acontecimiento más duradero por su fama posterior: la insurrección de los sargentos de artillería del cuartel de San Gil, sin sus jefes y oficiales, pero a las órdenes del general Pierrad. Esta sublevación fue seguida el 23 de intentos en Cataluña, pero como el resto del país no se sublevó a la vez - cosa frecuente en los pronunciamientos - los sargentos fueron vencidos, y lo mismo Milans del Bosch y sus amigos catalanes, que encontraron en Francia su salvación. Durísima represión se ejerció sobre los sargentos $\left({ }^{76}\right)$.

Ya era imposible aguantar por más tiempo a Isabel II. Los preparativos se hacían febrilmente, la conspiración crecía. Una entrada por tierras de Huesca en 1867 no dio todavía el resultado apetecido $\left({ }^{77}\right)$. Al final, en Septiembre de 1868, la escuadra

(M) Cf. Rispa y Perpiña, ob. cit., p. 61 ss.

(T5) Cf. F. G. Bruguera, Histoire contemporaine d'Espagne 1789-1950, París, Ophrys, 1953, pp. 246-247. Andrés Sánchez del Real, Emilio Castelar, Barcelona, Mañero, 1873, pp. 128-136.

(76) Q£ Pérez del Alamo, ob. cit., pp. 94-98. Enrique Rodríguez Solís, Memorias, Madrid, Plutarco, 1931, pp. 35-43. Es muy curiosa la novela de Vicente Moreno de la Tejera, La sangre de un héroe, Madrid, Robles y cía, s.a., que trae al final la lista de todos los fusilados.

(TT) Cf. Juan Massanet y Ochando, Memoria sobre los sucesos de Aragón en agosto de 1867. Madrid, Imp. de Tejado, 1868. Eugenio García Ruiz, Le Revolución en España, París, Ch. Lahure, Octubre de 1867. 


\section{Revueltas y Revoluciones en España}

fondeada en Cádiz, de acuerdo con los militares y con los partidos, dio el grito de insurrección, que rápidamente fue . secundado en todo el país por las Juntas clandestinas o que inmediatamente se fundaron.

De manera que la revolución de 1868, la gloriosa revolución de Septiembre, fue un pronunciamiento militar de acuerdo con hombres civiles, inmediatamente secundado por el pueblo. La narración de lo sucedido en numerosos puntos de España adquiere tintes inconfundiblemente democráticos. Pero nunca se mezclaron ambos elementos, el militar y el democrático. Las Juntas provinciales querían repetir el programa de 18Q8, tan buscado a lo largo del siglo XIX, pero Prim impuso su criterio: Monarquía, aun con otra dinastía, sometimiento de las Juntas y de los Voluntarios de la Libertad, control del Ejecutivo. El instrumento para burlar la revolución popular fue la Junta revolucionaria de Madrid, quien abusando de sus poderes, reconoció al Gobierno provisional, es decir a Prim y a los generales $\left({ }^{78}\right)$.

No es de este lugar detallar las diferentes candidaturas al trono. Sí, en cambio, decir que el desencanto popular produjo los alzamientos republicanos de 1869 , a cuya represión se aplicó el ejército $\left.{ }^{79}\right)$. Como en ningún momento en el curso del llamado Sexenio (1868-1874) hubo una profunda reforma de la Hacienda, la contrarrevolución vendrá por sí sola, por agotamiento y conspiración, y los mismos hombres de la situación de 1868, con muy pocas excepciones, se incorporarán a la contrarrevolución borbónica.

Antes de llegar a este resultado, las Cortes han aprobabo la Constitución de 1869 , la más avanzada del país, que vuelve a enlazar con la de 1812, y se ha proclamado rey de España a Amadeo I de Saboya, y por abdicación de éste, en 1873 las dos cámaras reunidas han proclamado la Primera República. No faltaron los conflictos: guerra de liberación en Cuba, nueva

(78) Cf. Manuel Ibo Alfaro, Historia de la interinidad española, 2 vols., Madrid, Alvarez, 1871 y 1876. Felipe Ducazcal, «Memorias de un empresario", Heraldo de Madrid, N. ${ }^{\circ}$ s de $4,8,12,22$ y 28 Nov. y de 4 y 17 Die. 1890. Mario Méndez Be jarano, Idealismo jurídico-político e historia interna de la Revolución de Septiembre de 1868, Madrid, Real Aead. de Jurisprudencia y Legislación, 1919 (1. ${ }^{a}$ ed. 1889). MM. de Lara, El cronista de la revolución española de 1868, Barcelona, Celestino Verdaguer, 1869. Alberto Gil Novales, La Revolución de 1868 en el Alto Aragón, Zaragoza, Guara, 1980.

$\left.{ }^{79}\right)$ Cf. Romualdo Lafuente, Málaga y sus opresores; relato verídico de los últimos sucesos de Málaga, Orán, 1869. Amallo Gimeno y Cabañas: El partido republicano de Valencia ante la Historia, Valencia, 1870. 
guerra carlista en el Norte, insurrección cantonal por impaciencia de los federales y de sus aliados los intemacionalistas, pues desde 1868 las doctrinas de Bakunin, difundidas por Giuseppe Fanelli, se han adueñado de gran parte del proletariado español.

Hay falta de entendimiento entre los republicanos antiguos y los nuevos, los ex-radicales que habían sido partidarios de Amadeo. Prohombres radicales, como Martos, intentan repetidas veces el golpe de Estado. Frente a la triple subversión, carlista, cubana y cantonal, los gobernantes de la República, no obstante con frecuencia su altura moral, no encuentran más solución que el restablecimiento de la disciplina en el ejército, puesto en manos de generales monárquicos y contrarrevolucionarios. El golpe de Estado del general Pavía, que disuelve manu militari las Cortes, es la consecuencia de esta política. La Restauración no se hace esperar: el 29 de Diciembre de 1874 el general Martínez Campos, al frente de la brigada Dabán, proclamaba a Alfonso XII en Sagunto $\left.{ }^{80}\right)$.

No termina con ello la historia revolucionaria de España. El siglo siguiente se iba a revelar igualmente conflictivo e igualmente insatisfactorio. España en este lapso se ha transformado: va siendo cada vez más un país burgués, con resabios arcaicos y gran dependencia del exterior. El pueblo, mientras tanto, ha buscado su liberación con una tesonera acometividad, y aunque tendrá momentos de euforia, el pasado le pesa y siempre la recaída es más dolorosa. Por lo menos la conflictividad nacional ha contribuido a desenmascarar a las fuerzas de la reacción, que ya no podrán abroquelarse en palabras cándidas y generosas. Y otra consecuencia importante: a lo largo del siglo XIX, cualquiera que sean las ideologías proclamadas, la actitud, sincera o calculista, del revolucionario es lo esencial, pues en esa centuria se irá dando un cambio paulatino de fuerzas que pasarán de la revolución clásica decimonónica a la reacción, ya en términos del siglo XX. Esta inserción de ex-izquierdismo en las sucesivas reacciones, y no sólo las actitudes políticas,

$C^{\circ}$ ) Cf. Francisco Pi y Margall y Francisco Pi y Arsuaga, Historia de España en el siglo XIX, Barcelona, Miguel Seguí, 1902, t. V., C.A.M. Hennessy, La República federal en España, Madrid, Aguilar, 1966. Nelly Clémessy, UEspagne de la Restauration, París, Bordas, 1973 Earl R. Beck, A Time of Triumph and of Sorrow. Spanish Politics during the reign of Alfonso XII, Southern Illinois Univ. Press 1979. A. Houghton, Les origines de la Restauration des Bourbons en Espagne, Paris, Plon, 1890. Manuel Espadas Burgos, Alfonso XII y los origenes de la Restauración, Madrid, CSIC, 1975. 


\section{Revueltas y Revoluciones en España}

sino las fuerzas sociales representadas, contribuirá de manera eminente a la fuerza del franquismo, el fenómeno social y político más importante de nuestra época en España. Pero desarrollar este tema no cabe en los límites del presente trabajo. 